\title{
Analysis of Tunnel Lining Failure Mechanism under the Action of Active Fault
}

\author{
Sujian Ma $\mathbb{D}^{1},{ }^{1}$ Liang Zhang $\mathbb{D}^{1},{ }^{1}$ Dong Wang, ${ }^{2}$ XinRong Tan, ${ }^{2}$ Sifeng Li $\mathbb{D}^{3},{ }^{3}$ and Yang Liu ${ }^{1}$ \\ ${ }^{1}$ Department of Civil Engineering, Southwest Jiaotong University, Chengdu 610031, China \\ ${ }^{2}$ China Railway Eryuan Engineering Group Co. Ltd, Chengdu 610031, China \\ ${ }^{3}$ Zhongke (Hunan) Advanced Rail Transit Research Institute Co. Ltd, Zhuzhou 412000, China
}

Correspondence should be addressed to Sujian Ma; masujian@my.swjtu.edu.cn and Liang Zhang; zhangliangdpme@ my.swjtu.edu.cn

Received 4 March 2021; Accepted 1 July 2021; Published 20 July 2021

Academic Editor: Gang Fan

Copyright (C) 2021 Sujian Ma et al. This is an open access article distributed under the Creative Commons Attribution License, which permits unrestricted use, distribution, and reproduction in any medium, provided the original work is properly cited.

\begin{abstract}
The underground structure that crosses the active fault will cause more serious damage under the dislocation of the active fault. Relying on an actual tunnel in the southwest mountainous area to establish a three-dimensional finite element model, the failure mechanism of the tunnel under strike-slip and thrust fault dislocation is revealed from the lining deformation, stress distribution, and plastic zone distribution, and the results show that the damage range of the lining distributes in the area of the fracture and the damage effect is greatly affected by the movement amount of the active fault. The lining damage under the active fault dislocation is mainly tensile damage, while the lining under the thrust fault dislocation shows compression damage on both sides of the fracture when there is a fracture with a large dip angle. The development range of plastic zone is positively correlated with the dip angle of the fracture and the amount of movement, and the development range is negatively correlated with the dip angle of the fracture and positively correlated with the amount of dislocation. The plastic zone range can be predicted, and the key monitoring range can be set according to the movement form of the active fault, the dip angle of the fracture zone, and the amount of fault movement.
\end{abstract}

\section{Introduction}

The underground structure has better seismic performance than the above-ground structure due to the restriction of the surrounding rock, but for the tunnel structure that crosses the fault, the degree of earthquake damage will be greatly increased [1-6], and the main reason is that the active fault movement causes the tunnel lining to collapse, which causes substantial economic losses. Relevant regulations [7] stipulate that, to prevent structural damage caused by fault movement, the site selection of buildings should avoid active faults. However, the geological conditions in southwest area of China are relatively complex, and active faults are widely distributed. With the implementation of the Western Development strategy and the development of the "One Belt, One Road" policy, the design and planning of engineering routes are more inclined to functional requirements, which has increasingly led to the fact that tunnels inevitably cross a large number of faults [8-10].

For tunnels crossing the active fault, domestic and overseas experts have done a lot of research in the fields of model testing, numerical simulation, and statistical analysis. In the field of statistical analysis and research, Toeher [11] used statistical regression methods to establish a statistical relationship between the magnitude of the earthquake and the length of the surface rupture caused by the active fault based on the seismic damage data. Matsuda Tokihiko [12] calculated multiple sets of Japanese earthquake record data and established a statistical relationship between magnitude and surface rupture based on the length of the surface rupture zone caused by an earthquake. In the field of model test analysis, Geng et al. [13] used shaking table tests to study the dynamic response of tunnels traversing fault zones under earthquake action and proposed a reasonable fortification 
length of fault-moving tunnels at a specific dip. Liu et al. [14] studied the force characteristics of the lining under the earthquake action and the acceleration amplification effect by controlling the test materials, the similarity ratio, and other parameters through the shaking table comparison test through the fault and, based on this, studied the development of tunnel cracks. Xin [15] carried out seismic shaking table tests on the seismic damage mechanism of the tunnel structure, studied the antivibration effect of the tunnel crossing fault, and established the time history evolution law of the tunnel and surrounding rock model damage. In the field of numerical simulation, Zhou et al. [6] established a three-dimensional finite element model using FLAC3D relying on the tunnel actually traversing the strike-slip fault, studied the mechanical effects of the tunnel lining under the movement of the strike-slip fault, explored the dynamic response law of the tunnel under the action of seismic wave, and obtained the antidistortion and seismic fortification length. Ramaneharla and Meguro [16] used the Applied Element Method and finite element calculation method to simulate and analyze the response of the overlying soil under the action of a tilt-slip fault and found that the greater the amount of bedrock movement, the greater the surface movement produced, and the more developed the soil fractures in high-stress areas. Huang et al. [17-19] make a two-dimensional time-history analysis of the selected soiltunnel shape through numerical parameter studies and determined the optimal intensity measure in the probabilistic seismic demand model of circular tunnel in soft soil.

The above studies are of important guiding significance for the construction of tunnels crossing the active fault zone, but there are still some deficiencies. Limited by the research conditions at this stage, the data required for statistical analysis is substantial and complex. The size of the model test is generally small, and there are few studies considering the longitudinal direction of the tunnel. Numerical simulation of structural constitutive relationship mostly adopts elastoplastic constitutive, which lacks the analysis of the damage structure of tunnel lining.

Relying on an actual tunnel in China, and using ABAQUS to establish a three-dimensional finite element model, this paper studies the failure of the tunnel lining under two fault movements, strike-slip and thrust under different fault angles and different dislocation amount of active fault, and reveals the failure mechanism of the lining from the three aspects of displacement and deformation, stress distribution, and the development of the plastic zone along the longitudinal lining of the tunnel, to provide a reference for the actual tunnel engineering through the active fault.

\section{Finite Element Numerical Model Establishment and Parameter Selection}

Relying on a domestic actual tunnel project, this paper established three-dimensional finite element models of different dip angles and different fault dislocations under strike-slip and thrust fault based on the finite element analysis software ABAQUS. According to the survey data, in the early stage of the project, the width of the model fracture is $40 \mathrm{~m}$, and the model is established by taking $180 \mathrm{~m}$ before and after the fracture. Since the shape of the tunnel in the actual project is not a perfect circle, the cross-sectional shape of the tunnel is drawn using a five-center circle, with the maximum inner diameter of $10 \mathrm{~m}$, the lining wall thickness of $0.5 \mathrm{~m}$, and the buried depth of $28 \mathrm{~m}$. According to the current experience in tunnel construction, it is believed that the transverse section size should be 5-10 times the tunnel section size. After 5 times, the artificial boundary will have little effect on the calculation results [20]. Therefore, the cross-sectional size of the model is set to 7 times the maximum size of the tunnel. The size of the model is $400 \mathrm{~m}$ (length) $\times 70 \mathrm{~m}$ (width) $\times 70 \mathrm{~m}$ (height), and the schematic diagram of the calculation model is shown in Figure 1.

Fault dislocation is realized by constraining the boundary conditions of the foot wall area and applying displacement loads to the hanging wall. Considering the most disadvantageous effects, when the fault movement rate is low, the overlying soil will undergo sufficient deformation, which will lead to the maximum damage caused by the fault to the tunnel [21-23]. Therefore, the rate at which the fault starts to move is set to $0.1 \mathrm{~m} / \mathrm{s}$. After a certain level, the rate of fault movement increases to give the soil sufficient time to deform.

Although the actual soil is a heterogeneous semi-infinite space, in order to truly simulate the failure process of tunnel lining under active fault dislocation, the model soil layer is assumed to be an ideal elastoplastic material, and the Mohr-Coulomb constitutive is adopted. The soil layer parameters are set according to the actual engineering survey results, as shown in Table 1 . The material of the tunnel lining is C55 concrete, and the concrete damage plastic constitutive is adopted in the model. According to the relevant specifications [24], the elastic-plastic stress-strain relationship of lining concrete is defined, and the specific parameters of lining are shown in Table 2. Considering the difference in material properties between the tunnel lining and the surrounding rock and soil, the contact between the two is set as friction, and the friction coefficient is 0.4 [25].

The simulation analysis is divided into three steps. Firstly, the unexcavated rock and soil are balanced by the initial ground stress, so that there is no stress disturbance and deformation under the action of its own weight; that is, the long-term consolidation and deposition of the soil are simulated. Secondly, to simulate the tunnel excavation and lining construction, the surrounding rock loads all act on the lining, and the lining is not allowed to deform. Finally, the displacement load is applied, the restraint of the boundary around the hanging wall is released, the load along the angle of the fracture zone is applied, and the restraint of the foot wall remains unchanged. The displacement load is shown in Figure 2, and the model meshing diagram is shown in Figure 3. In the process of initial ground stress balance and tunnel and lining construction, in order to achieve the simulation consistent with the actual situation, normal constraints are applied at the bottom and lateral boundary of the model, and the three directions of the lining are constrained, as shown in Figure 4(a). When the fault begins to move, the normal constraint on the hanging wall of the fault is released, and a displacement load is applied to realize the movement of the fault, as shown in Figure 4(b). 


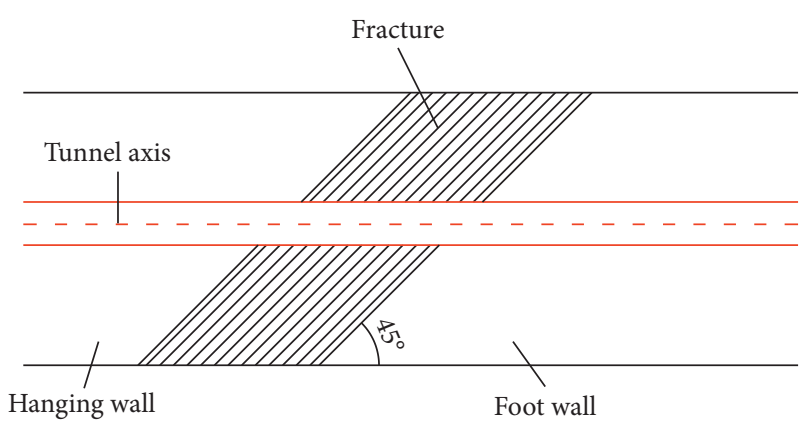

FIgURE 1: Schematic diagram of the model.

\section{Analysis of Tunnel Lining Safety under Different Dip Angles of Active Faults}

Strike-slip faults are large-scale translational faults. The hanging wall moves in translation along the slip surface of the fault zone. The stress source of relative motion is mainly the shear force on both sides. The interruption surface of the movement process is straight and smooth, and the shearing effect is obvious [26]. The damage to the arch waist of the tunnel lining is more serious, so this article focuses on selecting the measurement points at the arch waist for analysis. Thrust fault is a low-angle entry fault with a large displacement distance, showing strong compression and fracture [27], so the dip angle of the fault zone is increased by $30^{\circ}$ in the thrust fault model. Since the overall trend of the deformation of the thrust fault is the vertical displacement along the slip surface of the fracture, the main damage area of the tunnel lining in this case is the vault, so this paper focuses on selecting the measurement points on the vault for analysis.

In this paper, the dip angles of the strike-slip fault are $45^{\circ}$ $(\pi / 4), 60^{\circ}(\pi / 3), 75^{\circ}(5 \pi / 12)$, and $90^{\circ}(\pi / 2)$, and the dip angles of the thrust fault are $30^{\circ}(\pi / 6), 45^{\circ}(\pi / 4), 60^{\circ}(\pi / 3), 75^{\circ}(5 \pi /$ $12)$, and $90^{\circ}(\pi / 2)$.

3.1. Response Analysis of Lining Displacement and Deformation of Tunnels with Different Dip Angles. The displacement diagram of the arch waist of the tunnel lining along the longitudinal direction under the $3.5 \mathrm{~m}$ of the hanging wall of the strike-slip fault is shown in Figure 5(a). The displacement and deformation diagram of the arch waist of the tunnel lining along the longitudinal direction under the $0.8 \mathrm{~m}$ movement of the hanging wall of the thrust fault is shown in Figure 5(b).

As can be seen from the lining displacement curve in Figure 5, the fault dislocation drives the lining in the corresponding area to move in the same direction, and the lining displacement curve in the longitudinal direction of the tunnel has a dislocation platform, and the range is roughly the same as the bottom area of the hanging wall. The displacements of the lining platform of the tunnel in the movement direction are $3.5 \mathrm{~m}$ and $0.8 \mathrm{~m}$, which are consistent with the amount of fault dislocation. The lining displacement curves under different dip angles of the active faults are similar in shape and distributed in an "S" shape.
The deformation of the lining appears steeply in the fracture along the longitudinal direction of the tunnel. With the change of the dip angle, the range of the steep drop of the curve and the slope of the curve will not change significantly, and the curve moves to the foot wall with the increase of the dip angle of the fracture. The starting point of the steepdescent section of the strike-slip fault at a dip angle of $45^{\circ}$ is about $140 \mathrm{~m}$, while the starting point of the steep-descent section of the thrust fault at a dip angle of $30^{\circ}$ is about $100 \mathrm{~m}$. With the continuous increase of the dip angle of the fracture, the starting point of the $90^{\circ}$ dip of the two active faults is about $180 \mathrm{~m}$. It can be inferred that the failure area of the tunnel passing through the active fault area with different dip angles is roughly concentrated in the fracture, and the deformation has little correlation with the dip angle. In addition, strike-slip faults and thrust faults have similar shapes along the displacement application direction, while the displacement curve of the thrust fault is uplifted in the hanging wall at a dip angle of $30^{\circ}$, which is speculated that it may be caused by the uneven deformation of the upper soil due to the concentrated load at the lower part.

\subsection{Stress Response Analysis of Tunnel Lining with Different} Dip Angles. The lining material is C55 concrete, which can withstand high pressure. Therefore, the maximum principal stress is used to analyze the stress response of the lining under fault movement. The stress distribution of the lining under active fault dislocation with different dip angles is shown in Figure 6.

It can be seen from Figure 6(a) that the maximum principal stress at the hanging wall and foot wall is basically 0 when the strike-slip fault displacement is $3.5 \mathrm{~m}$, and the maximum value of the maximum principal stress along the longitudinal length of the tunnel appears in the fracture. When the dip angle is $45^{\circ}$ and $60^{\circ}$, the maximum principal stress of the lining along the longitudinal direction is the tensile stress, and the maximum is concentrated near $200 \mathrm{~m}$; that is, the maximum stress occurs in the middle of the intersection of the fracture and the lining. With the increase of the dip angle, the maximum value of the maximum principal stress is basically unchanged, and the lining in the central area needs to be monitored. When the dip angle is $75^{\circ}$ and $90^{\circ}$, the lining appears compressive stress along the longitudinal direction, and the maximum compressive stress appears near $250 \mathrm{~m}$. As the dip angle increases, the stress curve gradually moves to the foot wall, which is consistent with the distribution law of the lining displacement curve.

It can be seen from Figure 6(b) that when the thrust fault displacement is $0.8 \mathrm{~m}$, the maximum principal stress of the lining in the hanging wall and foot wall areas fluctuates slightly and is basically 0 . The maximum principal stress along the longitudinal direction of the tunnel appears in the fracture. The maximum principal stress along the longitudinal length of the tunnel is basically the tensile stress. When the dip angle is $30^{\circ}$, the maximum tensile stress is located near $100 \mathrm{~m}$, while the maximum tensile stresses of other dip angles are basically located at the bottom of the intersection of the fault and the hanging wall. It is speculated that the 
TABLE 1: Material parameters of surrounding rock.

\begin{tabular}{lccccc}
\hline Model & Density $\left(\mathrm{kg} / \mathrm{m}^{3}\right)$ & Elastic modulus $(\mathrm{MPa})$ & Poisson ratio & Internal friction angle $\left(^{\circ}\right)$ & Cohesion $(\mathrm{kPa})$ \\
\hline Fault & 2300 & $1.6 \times 10^{3}$ & 0.4 & 28 & $0.1 \times 10^{3}$ \\
Surrounding rock & 2400 & $3.5 \times 10^{3}$ & 0.32 & 35 & $0.4 \times 10^{3}$ \\
\hline
\end{tabular}

TABle 2: Material parameters of tunnel lining.

\begin{tabular}{cccccc}
\hline Model & Density $\left(\mathrm{kg} / \mathrm{m}^{3}\right)$ & Elastic Modulus $(\mathrm{MPa})$ & Poisson ratio & Compressive yield stress $(\mathrm{MPa})$ & Tensile yield stress $(\mathrm{MPa})$ \\
\hline Lining & 2400 & $2.648 \times 10^{4}$ & 0.167 & 32.5 & 2.64 \\
\hline
\end{tabular}

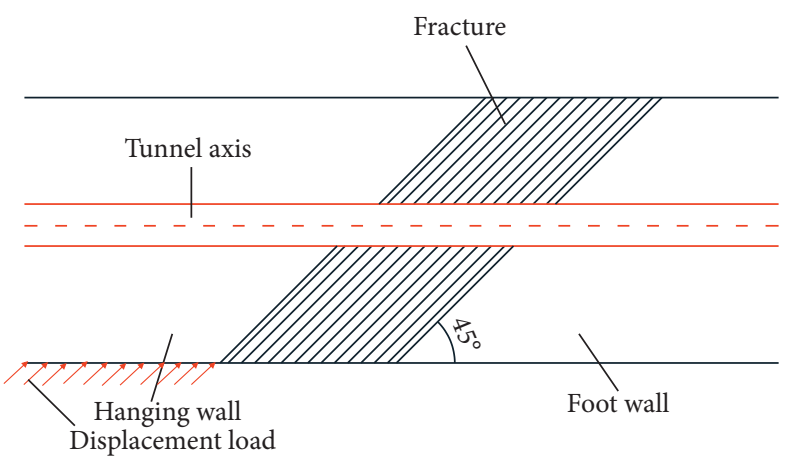

Figure 2: Schematic diagram of displacement load.

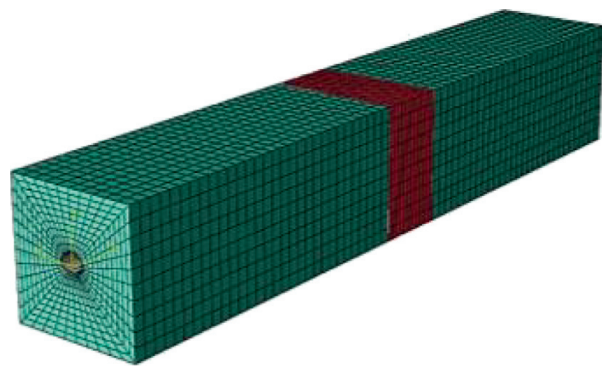

(a)

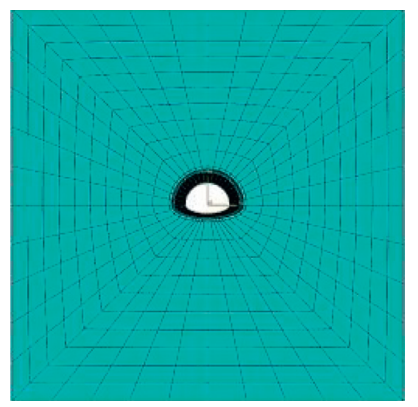

(b)

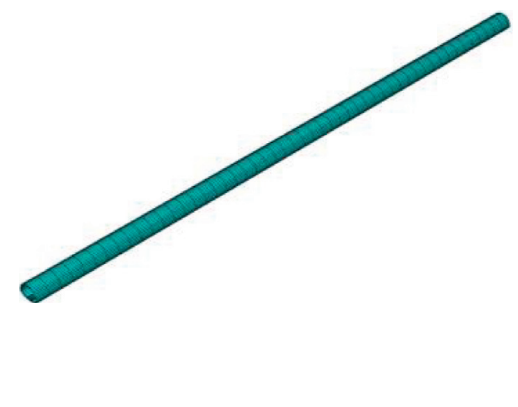

(c)

Figure 3: The meshing diagrams of each part of the model. The meshing diagram of the (a) model, (b) cross-sectional view of the model, and (c) division of tunnel lining.

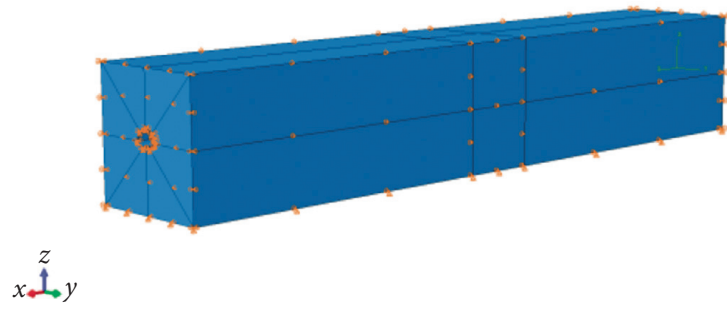

(a)

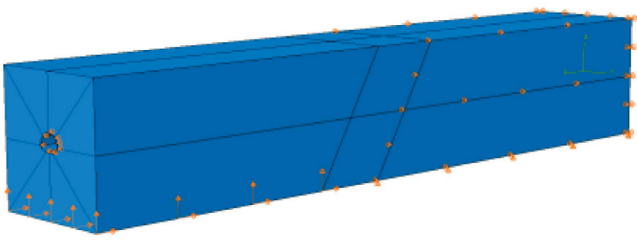

$\underset{x+y}{z}$

(b)

FIGURE 4: Boundary conditions of calculation model. (a) Initial boundary conditions of the model. (b) Boundary conditions of fault movement.

reason the maximum principal stress of the lining at $30^{\circ}$ shifts back from the predicted value may be the larger area of the top of the hanging wall, the smaller area of the bottom bearing displacement load, and uneven overall sliding. With the increase of the dip angle, the maximum tensile stress position gradually shifts from the hanging wall to the foot 


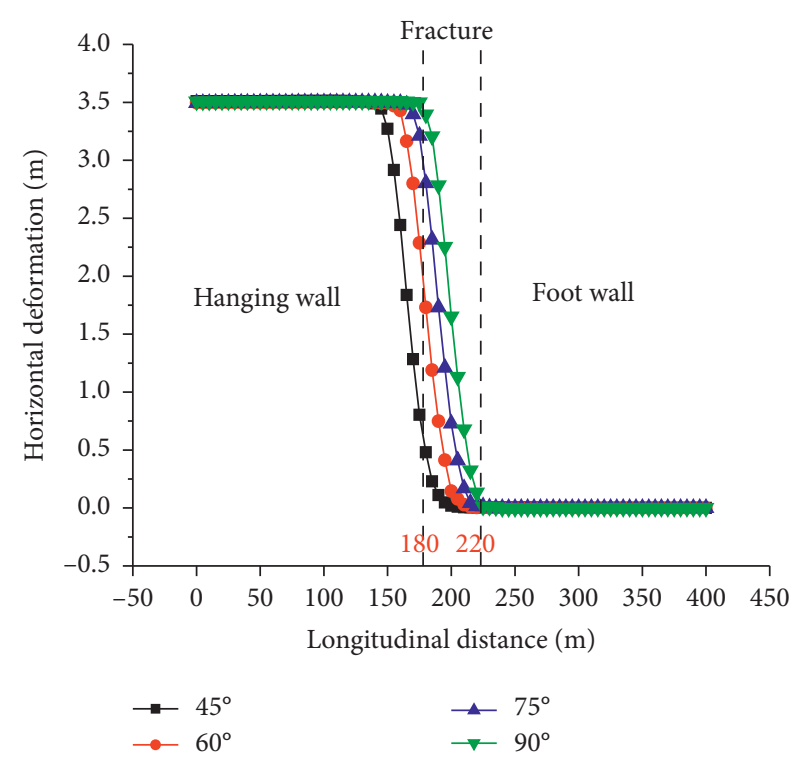

(a)

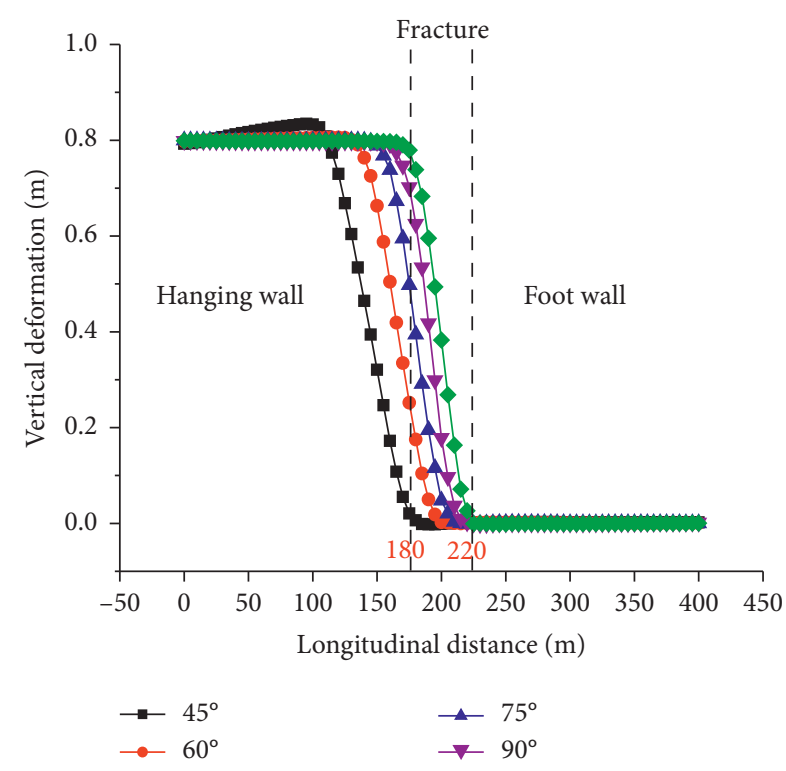

(b)

FIGURe 5: Displacement curves of tunnel lining with different dip angles. Lining displacement curves of different dip angles under (a) $3.5 \mathrm{~m}$ of strike-slip fault and (b) $0.8 \mathrm{~m}$ of thrust fault.

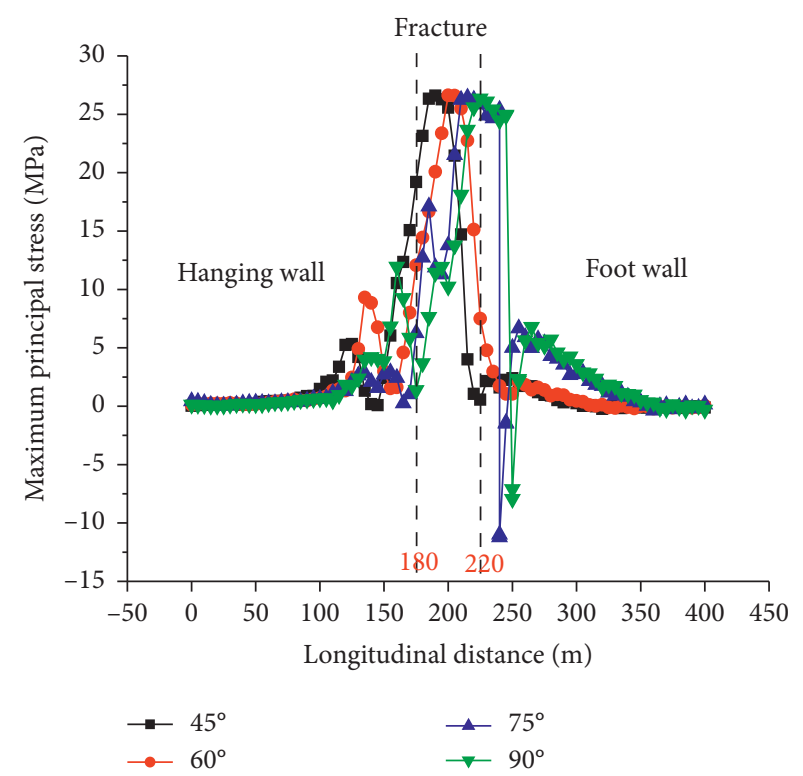

(a)

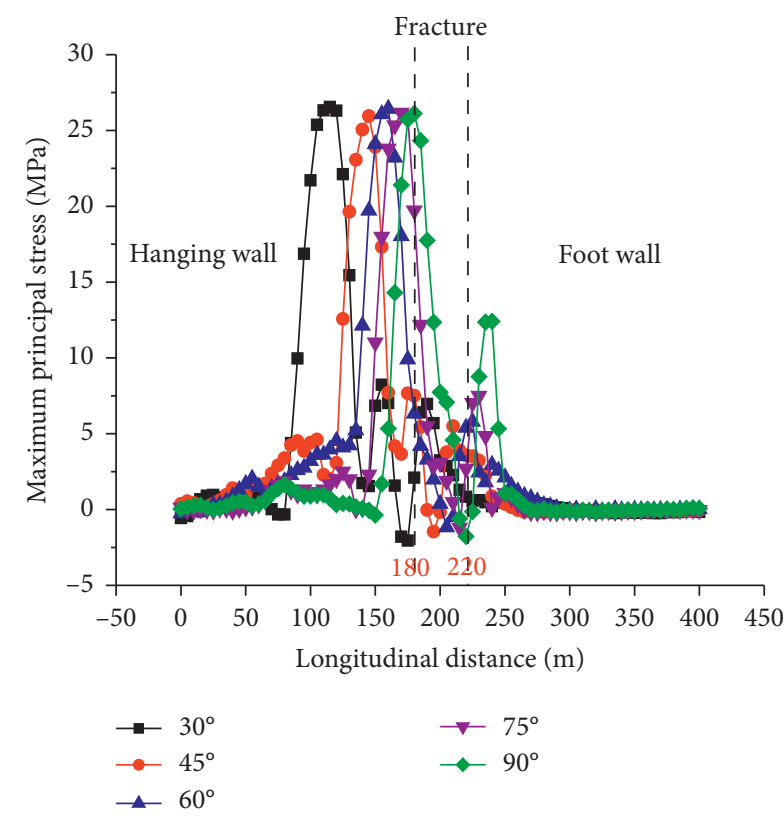

(b)

Figure 6: Maximum principal stress distribution curves of tunnel lining with different dip angles. The distribution of the maximum principal stress under (a) strike-slip fault and (b) under thrust fault.

wall. The damage position of the tunnel lining under fault movement is mainly determined by the bottom area of the hanging wall under the displacement load.

\subsection{Analysis of the Distribution of Plastic Zone in Tunnel} Lining with Different Dip Angles. The plastic zone distribution and range of the tunnel lining with strike-slip fault movement of $3.5 \mathrm{~m}$ and thrust fault movement of $0.8 \mathrm{~m}$ under 4 kinds of dip angles are analyzed. The cloud diagrams of the lining plastic zone range under strike-slip and thrust fault movement are shown in Figures 7 and 8 .

As can be seen from the above figures, when the strikeslip displacement is $3.5 \mathrm{~m}$, the plastic zone of the tunnel lining is concentrated in the vault and the bottom of the arch, whose location is mainly concentrated in the fracture, 
(a)

(c) (b)

(d)

Figure 7: Plastic zone of lining under strike-slip fault with different dip angles. Cloud diagram of the plastic zone of the strike-slip fault with (a) $45^{\circ}$ dip angle, (b) $60^{\circ}$ dip angle, (c) $75^{\circ}$ dip angle, and (d) $90^{\circ}$ dip angle.

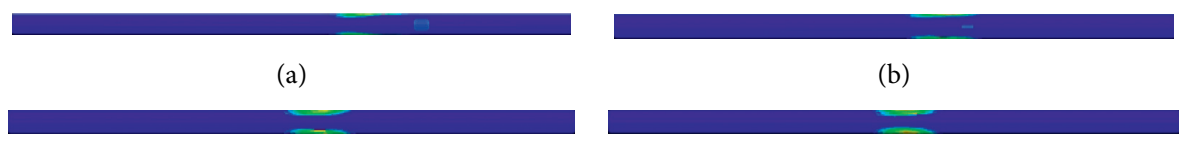

(c)

(d)

(e)

Figure 8: Plastic zone of lining under thrust fault with different dip angles. Cloud diagram of the plastic zone range of the thrust fault with (a) $30^{\circ}$ dip angle, (b) $45^{\circ}$ dip angle, (c) $60^{\circ}$ dip angle, (d) $75^{\circ}$ dip angle, and (e) $90^{\circ}$ dip angle.

and the distribution of the plastic zone is scattered from the central point in a discord shape. When the thrust fault displacement is $0.8 \mathrm{~m}$, the plastic zone of the tunnel lining is concentrated in both sides of the tunnel lining, and the starting position of the plastic zone is roughly located at the intersection of the fracture and the hanging wall. With the increase of the dip angle, the starting position of the plastic zone of the lining gradually moves to the foot wall, which is consistent with the stress distribution law of the tunnel lining. The development area of the plastic zone gradually increases and extends to the vault, and it can be inferred that when the fault moves, the plastic deformation first occurs on the arch side of the tunnel lining, which gradually extends from the arch side to the vault.

The extent of the plastic zone plays a vital role in the key monitoring of the lining after the fault occurs. According to the calculation results, the variation curves of the plastic zone of tunnel lining with the dip angle of fracture are drawn, as shown in Figure 9, the displacement of strike-slip fault is $0.8 \mathrm{~m}$, and the displacement of thrust fault is $3.5 \mathrm{~m}$.

Comprehensive analysis of Figure 9 shows that the plastic zone of the tunnel lining when the strike-slip fault is displaced $3.5 \mathrm{~m}$ is linear and positively correlated with the dip angle. The extent of the plastic zone of the lining increases with the increase of dip angle. The plastic zone range of the tunnel lining and the dip angle are logarithmic function and negatively correlated when the thrust fault is dislocated $0.8 \mathrm{~m}$, and the plastic zone range gradually decreases with the increase of dip angle. Therefore, under the dislocation of active faults, the range of the tunnel lining plastic zone can be calculated according to the dip angle and the key monitoring range can be set.

\section{Analysis of Tunnel Lining Safety under Different Displacements of Active Faults}

Fault movement is mainly divided into stick-slip movement and creeping movement. Stick-slip movement is a sudden rapid rupture movement, and creeping movement is a slow movement that occurs over time. Studies have shown that the slow movement of the fault gives the soil a sufficient deformation process, and the damage degree is greater than that of the stick-slip movement [28]. The slow movement of the fault has higher damage degree and happened in tunnel engineering. Therefore, this paper analyzes the failure modes of tunnel lining when the creeping movement of the fault occurs.

4.1. Deformation Response Analysis of Tunnel Lining under Different Movement Amounts of Active Faults. This paper selects strike-slip and thrust faults $0.8 \mathrm{~m}, 1.0 \mathrm{~m}, 1.2 \mathrm{~m}, 1.4 \mathrm{~m}$, $1.6 \mathrm{~m}, 2.0 \mathrm{~m}, 2.5 \mathrm{~m}$, and $3.5 \mathrm{~m}$ for analysis, and Figure 9 shows the displacement curve of the tunnel lining vault under different movement amounts when the dip angle is $90^{\circ}$.

It can be seen from Figure 10(a) that when the dip angle is $90^{\circ}$, the tunnel lining displacement curve under different displacements of strike-slip fault is distributed in an " $S$ " shape, and the tunnel lining in the hanging wall moves in the same form with the fault, whose displacement is consistent with the fault movement. The deformation curve of the lining along the longitudinal direction of the tunnel has a steep drop section, and all steep drop sections are located in the fracture. With the increase of the fault displacement, the slope of the displacement curve in the steep drop zone gradually increases. Therefore, the lining damage significant area under strike-slip fault is mainly located in the fracture, and the higher the fault displacement, the more serious the lining damage.

It can be seen from Figure 10(b) that the deformation curve of the tunnel lining under the thrust fault with $90^{\circ} \mathrm{dip}$ angle has the same shape as the displacement curve under the strike-slip fault in the respective load application directions, and both show "S" shape. The tunnel lining moves in the same form as the hanging wall along the displacement load application direction. Similar to the displacement curve of the strike-slip fault in the load direction, the lining displacement 


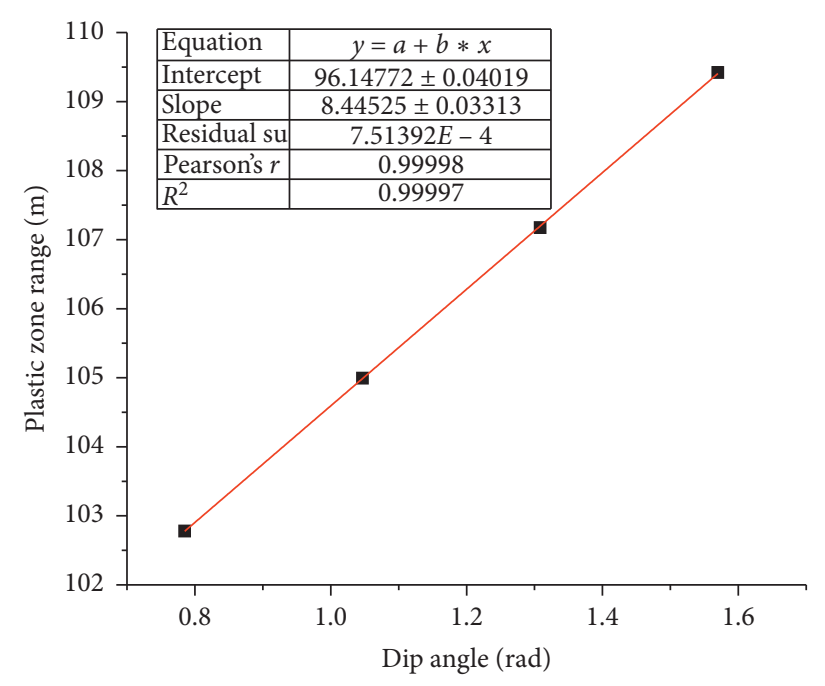

(a)

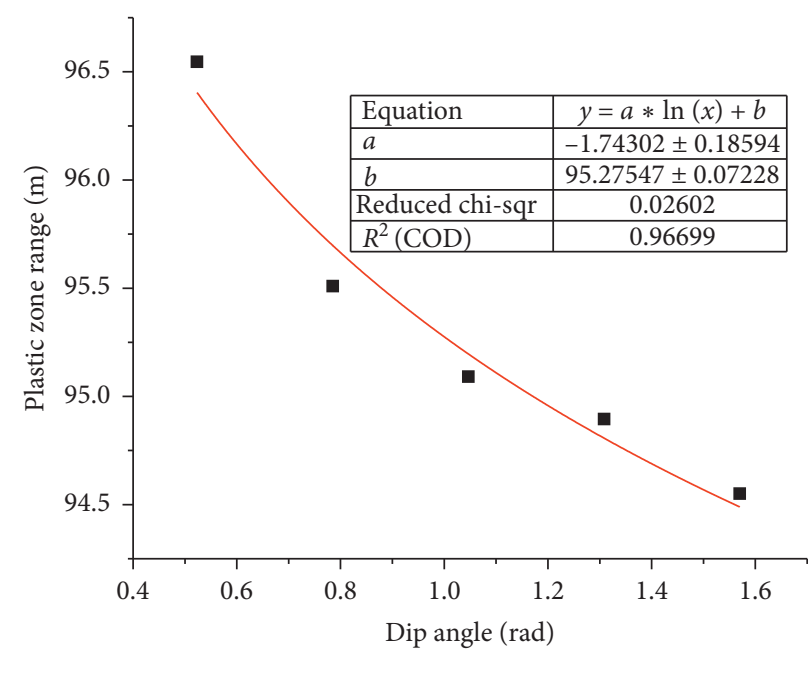

(b)

FIGURE 9: The curves of lining plastic zone range with different dip angles under active fault. The curve of plastic zone range under (a) strikeslip fault and (b) thrust fault with different dip angles.

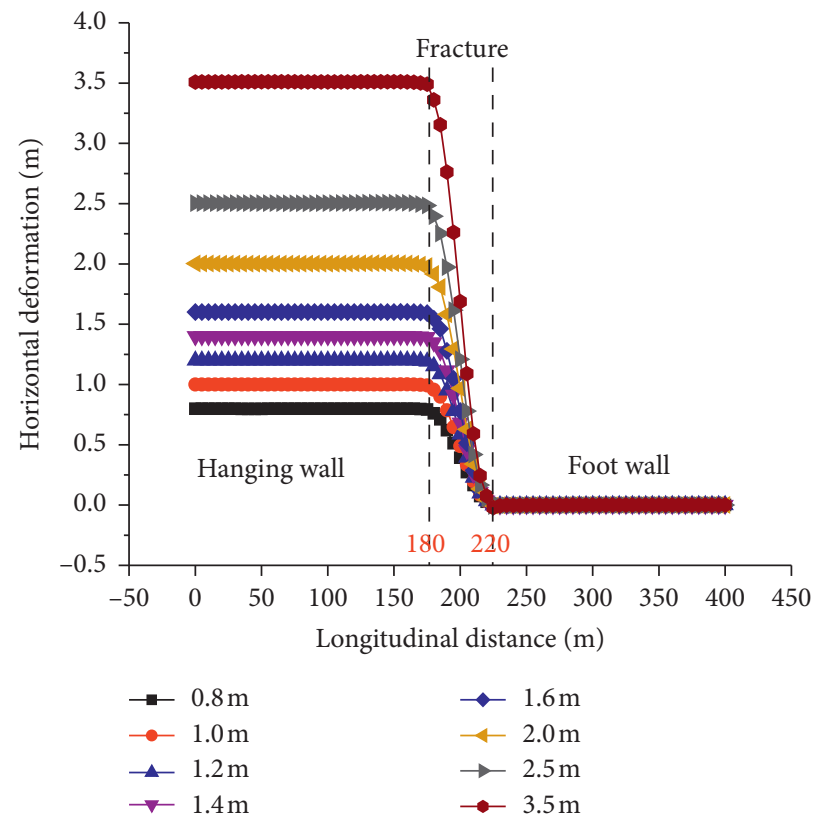

(a)

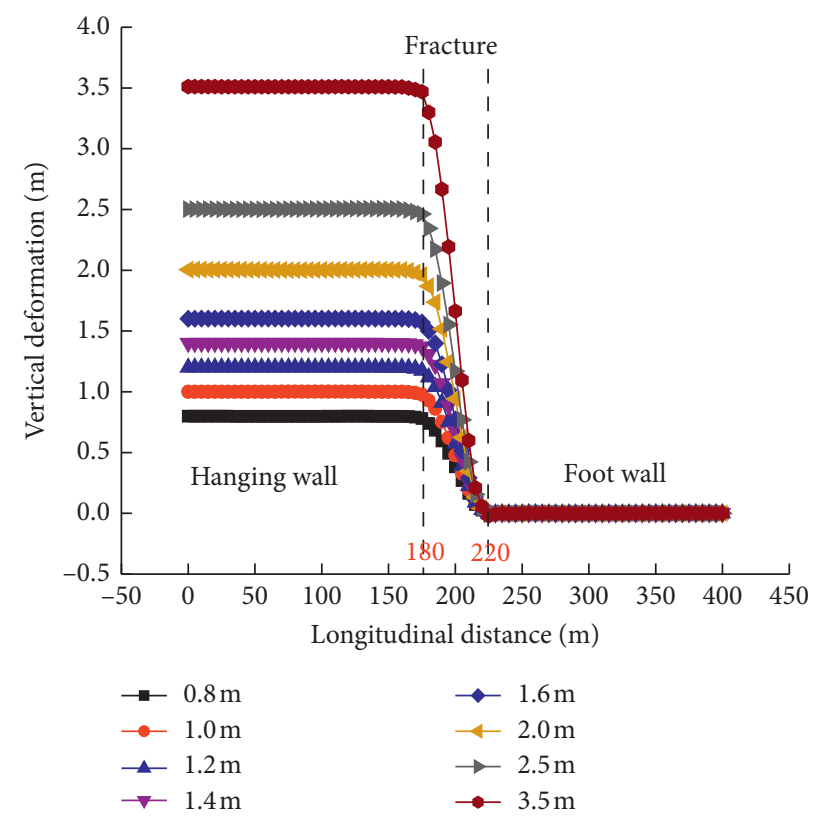

(b)

Figure 10: Lining deformation curves under different displacements of $90^{\circ}$ fault. The lining deformation curves under different displacements of (a) strike-slip fault and (b) thrust fault.

curve has a steep drop in the fault, and all is located in the fracture. As the displacement increases, the slope of the steepdescent curve continues to increase, and the lining located in the fracture zone is more likely to be damaged.

\subsection{Stress Response Analysis of Tunnel Lining under Different} Displacements of Fault. To explore the influence of the stress distribution on the tunnel lining under different faults of strike-slip and thrust, the maximum principal stress distribution along the longitudinal length of the tunnel was made according to the calculation results, as shown in Figure 11.

It can be seen from Figure 11(a) that the maximum principal stress distribution curves under different strikeslip faults are basically consistent in shape and maximum values. The maximum principal stress of the lining at the hanging wall and foot wall is basically 0 , and the maximum principal stress of the lining along the longitudinal length of the tunnel increases first and then decreases. The changing section of the curve as a whole is located between $150 \mathrm{~m}$ and $250 \mathrm{~m}$, and the maximum principal stress is located near 


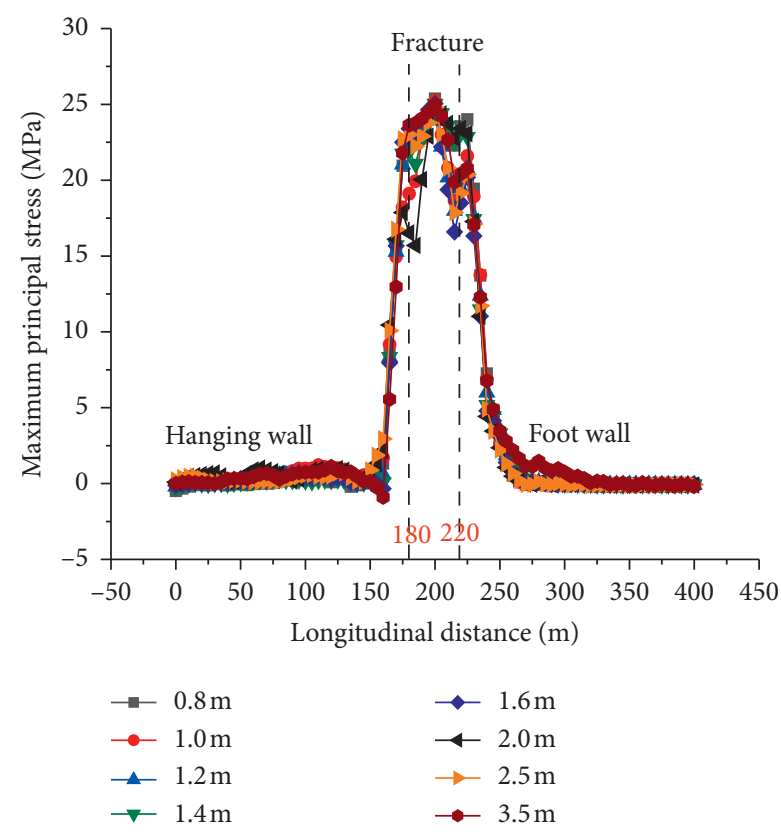

(a)

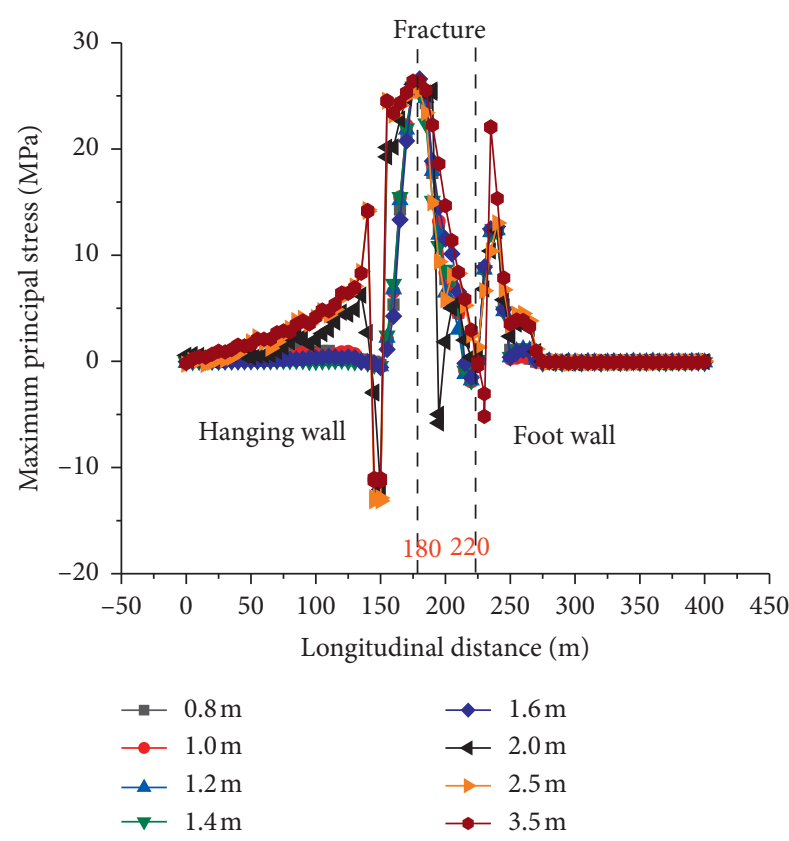

(b)

FIgURE 11: The distribution curves of the maximum principal stress of the lining under different displacements of active faults. The maximum principal stress distribution curves of the lining under (a) strike-slip fault and (b) thrust fault.

$200 \mathrm{~m}$. The overall curve is symmetrically distributed. Therefore, it can be inferred that the significant damage area of the tunnel lining under the strike-slip fault movement is located $50 \mathrm{~m}$ before and after the fracture, and the damage in the middle is the most significant. The maximum principal stress distribution of the tunnel lining under different strikeslip fault is roughly the same. It is speculated that this may be due to the damage to the middle of the tunnel lining before the fault displacement of $3.5 \mathrm{~m}$.

It can be seen from Figure 11(b) that the maximum principal stress distribution curve of the lining under the thrust fault is different from the strike-slip fault movement. The maximum principal stress distribution curves at $0.8 \mathrm{~m}$, $1.0 \mathrm{~m}, 1.2 \mathrm{~m}, 1.4 \mathrm{~m}$, and $1.6 \mathrm{~m}$ faults are similar, which are roughly symmetrical, while the maximum principal stress distribution curves at $2.0 \mathrm{~m}, 2.5 \mathrm{~m}$, and $3.5 \mathrm{~m}$ are roughly centrally symmetrical. The maximum principal stress of the lining at the hanging wall and foot wall of the thrust fault is basically zero, and the maximum principal stress change section of the lining is basically between $150 \mathrm{~m}$ and $200 \mathrm{~m}$, and the maximum stress is near $200 \mathrm{~m}$, which is similar to the stress distribution law of a strike-slip fault. In addition, the maximum principal stress under the thrust fault appears compressive stress, and the maximum compressive stress is at $150 \mathrm{~m}$ and $220 \mathrm{~m}$, which is consistent with the area of the fracture zone. Therefore, it can be inferred that the lining located within $50 \mathrm{~m}$ before and after the fracture zone undergoes significant tensile failure when the thrust fault is dislocated, and the lining located in the middle of the fracture has the most obvious damage. As the displacement of fault increases, compression failure occurred in the lining $50 \mathrm{~m}$ in front of the fracture.
4.3. Analysis of the Plastic Zone Range of the Tunnel Lining under Different Displacements. The development of the plastic zone of the tunnel lining under different displacements of the active fault has an important reference value for the key monitoring area of the tunnel crossing the active fault area. According to the calculation results of the model, the development cloud diagram of the plastic zone with different displacements of strike-slip and thrust fault at $90^{\circ}$ dip is obtained, as shown in Figure 12.

Comprehensive analysis of Figure 12 shows that the plastic zone of the tunnel lining under strike-slip fault is mainly concentrated in the vault and roughly located in the fracture. As the displacement increases, the plastic zone continues to increase and gradually gathers towards the vault. The distribution of the plastic zone in the vault is roughly the same as the distribution of the maximum principal stress under the strike-slip fault movement, and the damage to the lining in the fracture is the most significant. The plastic zone of the tunnel lining under the thrust fault movement is mainly concentrated in the lining arch waist, and the range is roughly located in the middle fracture. As the displacement increases, the extent of the plastic zone on both sides of the arch waist continues to increase, and the development of plastic zones at different parts of the strikeslip fault appears. Therefore, it can be inferred that the development of the plastic zone of the tunnel lining under the strike-slip fault is gradually extending from both sides of the arch waist to the vault, while the development of the plastic zone of the tunnel lining under the thrust fault gradually extends from the vault to both sides of the vault.

Comprehensive analysis of Figure 13 shows that when the dip angle is $90^{\circ}$, the development of the plastic zone of the 
(a)

(c) (b)

(d)

Figure 12: The cloud diagrams of plastic zone with different displacements under $90^{\circ}$ dip angle. Cloud diagram of plastic zone under strikeslip fault with (a) $0.9 \mathrm{~m}$ and (b) $1.1 \mathrm{~m}$. Cloud diagram of plastic zone under thrust fault with (c) $0.9 \mathrm{~m}$ and (d) $1.1 \mathrm{~m}$.

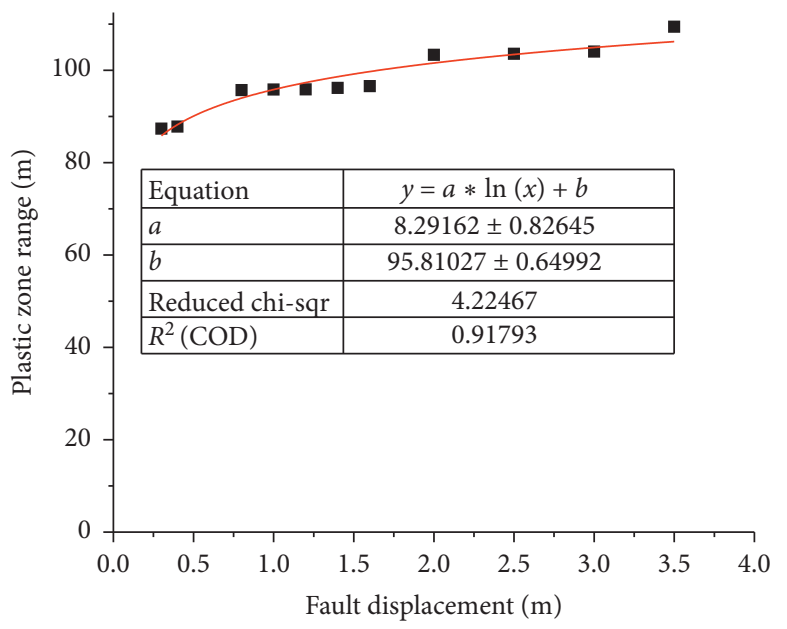

(a)

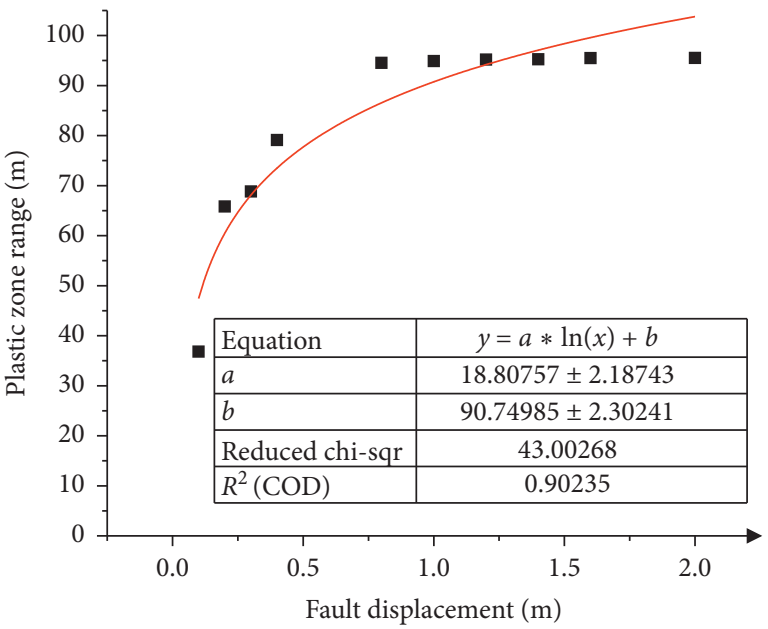

(b)

Figure 13: The development curves of the plastic zone range under different displacements of the active faults. Plastic zone range under different displacements of (a) strike-slip fault and (b) thrust fault.

active fault is distributed in a logarithmic function, and the development range of the plastic zone is positively correlated with the amount of movement, and with the increase of movement amount, the range of plastic zone gradually increases. Therefore, the key monitoring range of the lining under active fault movement should consider not only the influence of the dip angle of the fracture, but also the influence of the displacement of active fault.

\section{Conclusion}

In this paper, by establishing a three-dimensional finite element tunnel model under strike-slip and thrust fault movement, the tunnel lining displacement, maximum principal stress distribution, and the plastic zone development under different dip angles and different fault movement amounts are discussed. Thus, the damage mechanism of the lining under the active fault movement is revealed, and the conclusions are as follows:

(1) Under active fault movement, the tunnel lining moves in the same form with the hanging wall, and the displacement curve shows an "S"-shaped distribution. The significant area of failure is roughly located near the fracture. When the dip angle of thrust fault is less, the displacement load will result in uneven displacement upward transmission. The shape of the deformation curve of the lining under different displacements of the active fault is the same, showing an "S"-shaped distribution. The significant area of lining damage is also located near the fracture, and the damage effect becomes more significant with the increase of fault dislocation.

(2) The maximum principal stress at the hanging wall and foot wall under the active fault movement is basically 0 . The maximum principal stress under the movement of a strike-slip fault occurs in the central area of the fault zone and is mainly tensile failure. The maximum principal stress under the thrust fault movement gradually moves to the foot wall with the increase of the dip angle, and compressive failure also occurs. The significant damage area of the lining under the strike-slip fault is mainly tensile failure, while the compressive failure occurs when the thrust fracture is steep. The damage range is mainly affected by the dip angle of the fracture, while the damage effect is mainly affected by the increase of fault dislocation.

(3) The plastic zone of the tunnel lining under different dip angles strike-slip fault is concentrated in the fracture and develops from both sides of the arch waist to the arch top and arch bottom. The extent of the plastic zone gradually increases in a logarithmic 
function. The plastic zone of the tunnel lining under the thrust fault movement is also concentrated in the fracture zone, but it develops from the vault and arch bottom to both sides of the arch waist. The extent of the plastic zone is similar to the law of development under strike-slip faults, showing a gradual increase in a logarithmic function relationship.

\section{Data Availability}

The data used to support the findings of this study are available from the corresponding author upon request.

\section{Conflicts of Interest}

The authors declare that they have no conflicts of interest regarding the publication of this paper.

\section{Acknowledgments}

This study was supported in part by the Sichuan Provincial Science and Technology Support Project (Nos. 2020YJ0253, 2020YFSY0060, 2019JDRC0133, and 2019JDRC0134); Fundamental Research Funds for the Central UniversitiesInterdisciplinary Research Project (2682021ZTPY102); National Nature Science Fund Project (No. 52078426); National Key Research and Development Plan (No. 2018YFE0207100); China Railway Eryuan Engineering Group Co. Ltd Scientific Research Project (KYY2019034(1922) and KYY2019070(19-20)); and China National Railway Group Co. Ltd Scientific Research Project (Nos. SY2016G003 and N2020T004).

\section{References}

[1] P. Geng, C. He, and Q. X. Yan, "The current situation and prospect of seismic analysis methods for tunnel structure," China Civil Engineering Journal, vol. 46, no. S1, pp. 262-268, 2013.

[2] Z. B. Li, "Analysis on seismic technology of tunnels in areas with high seismic intensity," Building Technology Development, vol. 43, no. 5, pp. 88-89, 2016.

[3] L. M. Qu, X. M. Ding, G. Kouroussis, and C. J. Zheng, "Dynamic interaction of soil and end-bearing piles in sloping ground: numerical simulation and analytical solution," Computers and Geotechnics, vol. 134, Article ID 103917, 2021.

[4] Y. S. Shen, L. Z. Tang, and P. F. Zhou, "Research on antiseismic technology of Railway tunnel structure crossing soft and hard interface in strong earthquake area," Railway Standard Design, vol. 62, no. 10, pp. 123-129, 2018.

[5] J. S. Shi, Experimental and Numerical Study on the Damage of Overlying Soil and Tunnel Caused by Fault movement, Zhejiang University, Hangzhou, China, 2017.

[6] L. Qu, C. Yang, X. Ding, G. Kouroussis, and C. Zheng, “A continuum-based model on axial pile-head dynamic impedance in inhomogeneous soil," Acta Geotechnica, 2021.

[7] National Standard of the People's Republic of China, Code for Seismic Design of Buildings (GB50011-2010), China Construction Industry Press, Beijing, China, 2010.

[8] V. A. Kontogianni and S. C. Stiros, "Earthquakes and seismic faulting:effects on tunnels," Turkish Journal of Earth Sciences, vol. 12, no. 1, pp. 153-156, 2003.
[9] M. Russo, G. Germani, and W. Amberg, "Design and construction of large tunnel through active faults a recent application," in Proceedings of the International Conference of Tunnelling \& Under-ground Space Use, pp. 1-14, Istanbul Turkey, October 2002.

[10] Y. Zhao, Seismic Response Analysis of Subway Tunnel in Active Fault area, Institute of Engineering Mechanics, China Earthquake Administration, Heilongjiang, China, 2014.

[11] D. Toeher, "Earthquake energy and ground breakage," Bulletin of the Seismological Society of America, vol. 48, no. 2, pp. 147-153, 1958.

[12] M. Toshihiko, Research on Active Faults, Seismological Press, Beijing, China, 1983.

[13] P. Geng, Y. He, C. He, Q. L. Quan, and Q. X. Yan, "Study on the reasonable seismic fortification length of the tunnel crossing the fracture zone," Chinese Journal of Rock Mechanics and Engineering, vol. 33, no. 02, pp. 358-365, 2014.

[14] Y. Liu, J. Lai, J. P. Xin, X. D. Li, and R. J. Xing, "Dynamic comparative test research on seismic response law of tunnel crossing fault," Rock and Soil Mechanics, vol. 40, no. 12, pp. 4693-4702, 2019.

[15] C. L. Xin, Research on the Mechanism of Ground Motion Damage and Anti-seismic Measures for Tunnels Crossing faults, Southwest Jiaotong University, Chengdu, China, 2015.

[16] M. Ramaneharla, Numerical Modeling of Dip-Slip Faults for Studying Ground Surface deformation, Bulletin of Earthquake Resistant Structure Research Center, Institute of Industrial Science, The University of Tokyo, Tokyo, Japan, 2001.

[17] Z.-K. Huang, K. Pitilakis, S. Argyroudis, G. Tsinidis, and D.-M. Zhang, "Selection of optimal intensity measures for fragility assessment of circular tunnels in soft soil deposits," Soil Dynamics and Earthquake Engineering, vol. 145, Article ID 106724, 2021.

[18] Z.-K. Huang, K. Pitilakis, G. Tsinidis, S. Argyroudis, and D.-M. Zhang, "Seismic vulnerability of circular tunnels in soft soil deposits: the case of Shanghai metropolitan system," Tunnelling and Underground Space Technology, vol. 98, Article ID 103341, 2020.

[19] Z.-K. Huang and D.-M. Zhang, "Scalar- and vector-valued vulnerability analysis of shallow circular tunnel in soft soil," Transportation Geotechnics, vol. 27, Article ID 100505, 2021.

[20] W. Zhang, Research on Seismic Response and Damping Measures of Large-Diameter Shield Tunnel structure, Wuhan Institute of Rock and Soil Mechanics, Chinese Academy of Sciences, Wuhan, China, 2009.

[21] Z. Y. Chen and Y. Zhao, "Analysis of tunnel response caused by active reverse fault movement," in Proceedings of the 2019 National Engineering Geology Annual Conference, pp. 113118, The Geological Society of China: Editorial Office of Journal of Engineering Geology, Philadelphia, Pennsylvania, USA, 2019.

[22] M. L. Lin, C. F. Chung, and F. S. Jeng, "Deformation of overburden soil induced by thrust fault slip," Engineering Geology, vol. 88, no. 1-2, pp. 70-89, 2006.

[23] M.-L. Lin, C.-F. Chung, F.-S. Jeng, and T.-C. Yao, "The deformation of overburden soil induced by thrust faulting and its impact on underground tunnels," Engineering Geology, vol. 92, no. 3-4, pp. 110-132, 2007.

[24] GB 50010-2010, GB 50010-2010 Code for Design of concrete Structures, pp. 19-20, China Architecture \& Building Press, Beijing, China, 2015, in Chinese.

[25] H. Huo, Seismic Design and Analysis of Rectangular Undergroundstructures, pp. 23-28, School of Civil Engineering, PurdueUniversity, West Lafayette, IN, USA, 2005. 
[26] J. W. Xu, "On the main problems of strike-slip fault," Frontiers of Earth Science, vol. 1, no. 02, pp. 125-136, 1995.

[27] H. L. Song, C. H. Zhang, and G. H. Wang, Structural Geology, Geological Publishing House, Beijing, China, 2013.

[28] X. Z. Liu, X. L. Wang, and L. L. Lin, "Model experimental study on influence of normal fault with $60^{\circ}$ dip angle stick-slip movement on mountain tunnel," China Civil Engineering Journal, vol. 47, no. 2, pp. 121-128, 2014. 